\title{
The Impact of ICDL Training on Developing Digital Literacy of Young People
}

\author{
Mohammad Salim Al-Othman ${ }^{1}$ \& Israa Nazhat Abdullah $^{2}$ \& Saifuldeen H. Abdulrahman ${ }^{3}$ \& Adnan \\ Fadhil Khaleel $^{4}$
}

${ }^{1}$ IT Department, Faculty of Science, Tishk International University, Erbil, Iraq

${ }^{2}$ Computer Engineering Department, Faculty of Engineering, Tishk International University, Erbil, Iraq

${ }^{3}$ Department of Computer Science, DCSC, Knowledge University, Erbil, Iraq

${ }^{4}$ Adnan Fadhil Khaleel, Educational Counseling Department, College of Basic Education, University of Duhok

Correspondence: Mohammad Salim Al-Othman, Tishk International University, Erbil, Iraq.

Email: mohammad.salim@tiu.edu.iq

\section{Doi:10.23918/ijsses.v8i2p16}

\begin{abstract}
The purpose of this study is to examine how teaching ICDL courses could improve the IT skills of young people. A sample of 27 young participants was selected from Mosul city. A questionnaire and interviews regarding digital skills and knowledge were the data collection methods. The data were then analyzed to determine the current level of participants and to fulfill the objective of this study. At the end of the training course, the students were evaluated to analyze the learning outcomes of the course. According to the study findings, most of the participants improved their online and spreadsheets skills by an increase of 90 percent from their previously recorded results and around 50 percent increase for the computer and word processing essentials. The gender gap was not entirely evident in the conducted test as the participation rate of females was high and reached an approximation of $50 \%$ in total, however, female, and male counterparts of both age groups, proved competent during the tests, with males proving to be more successful in both age groups. This leads to the conclusion that more efforts are needed to rally females into being involved in the computer world and to challenge their male counterparts in computer literacy and in taking their future path in computer science majors. Additional ICDL training is also recommended to be given to IDPs and war-torn areas where a large percentage of youth lack the basic IT skills, as it is deemed useful to the recovery of their community and in turn, provide an adequate future to shape the return framework.
\end{abstract}

Keywords: IT Skills, Computer Training, ICDL Training, Digital Literacy, Software Application

\section{Introduction}

In today's world, the role of technology has become crucial. IT skills are important for performing simple, daily tasks related to social, education, and work aspects. Therefore, the ministries of education and higher education in both the Iraq and Kurdistan region have added IT courses throughout different levels in schools and as a mandatory course for first years' students in all universities of the country.

Received: March 14, 2021

Accepted: May 16, 2021

Al-Othman, M.S., \& Abdullah, I.N., \& Abdulrahman, S.H., \& Khaleel, A.F. (2021). The Impact of ICDL Training on Developing Digital Literacy of Young People. International Journal of Social Sciences \& Educational Studies, $8(2), 16-27$. 
International Computer Driving License (ICDL) training is one of the International programs found to fill the IT skills literacy gap. The role and influence of Information Technology (ICT) on today's world has become incredibly prominent where technology is integrating into all parts of our daily lives such as social, educational, medical, and industrial sectors. Consequently, it has become mandatory to teach IT courses in all Iraqi schools and universities. However, this involvement of IT courses is yet to be considered sufficient, due to the severe lack of computer labs in most public schools of Iraq and the Kurdistan region. The community needs IT and computer skills to ensure they can deal effectively with the current and future demands in terms of productivity and enhancing the quality of their lives. IT training centers in Iraq are offering different training courses starting from basic computer skills to professional training such as CISCO and MicroTek training of computer networks. Regarding basic IT courses, two main courses are currently available, first one is IC 3 certification (Internet Core Competency Certification) which is a global benchmark for basic computer literacy, including operating systems, hardware, software, and networks (Al-Hakeem \& Abdulrahman, 2017). While the second training is the ICDL training which has 3 modules, these modules are basic, intermediate, and advanced with each module comprised of different parts as seen in Fig. 1 below.
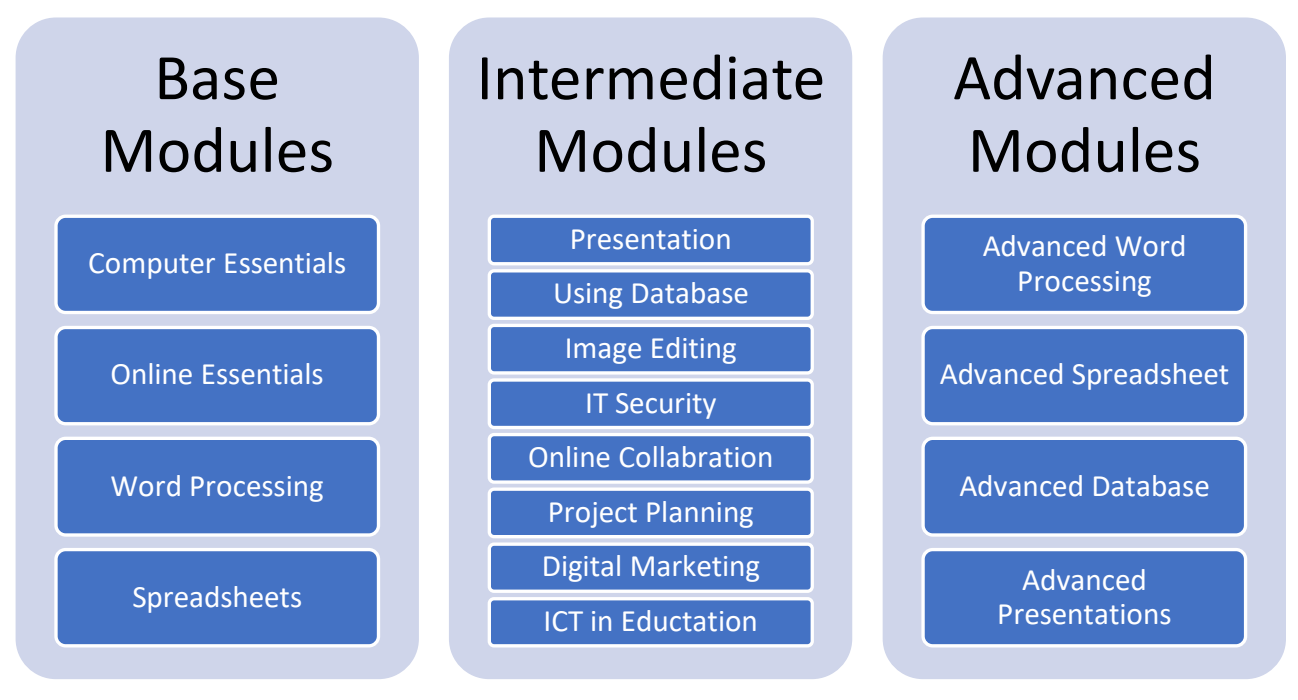

Figure 1: ICDL's three modules

IT training courses are aimed at improving the use of including International Computer Driving License (ICDL) in the daily life of participants. The ICDL, which is known as the European Computer Driving License (ECDL) within the European Union, is a certification proving basic proficiency in the use of certain types of software or computer systems (Csapo, 2002). The course aims to improve students' IT proficiency at two levels: IT skills and knowledge. Hence, the main purpose of this study is to evaluate the impact of ICDL training on the computer use of the young generation and whether the ICDL training contributes to increase their literacy.

\section{Literature Review}

Leahy and Dolan (2010) argued that technology and ICT literacy both play a vital role in the transformation of education and work practices. A business-related person will need the basic digital 
literacy competencies to have the ability to work in remote teams and to be conscious of the web and ongoing technological advances. Digital competencies offer numerous opportunities in education, business, and specific jobs. And as digital literacy continues to evolve and new technology emerges, similarly, a new challenge will arise to ensure that the people, of different ages and educational backgrounds, can attain and maintain a reasonable level of competence to benefit from the Knowledge Society.

Abuhmaid (2011) conducted a study aimed to explore the ICT courses' effectiveness within the Jordanian educational system. The study utilized a mixed-methods approach aimed to investigate Jordanian teacher preparation to use ICT to support teaching and learning. A combination of both questionnaires and case studies was used and obtained from a sample of 120 teachers to collect data before conducting the training. After findings of the ICT training courses which targeted two levels of skills, with ICDL as the most undertaken course, showed that $76.5 \%$ of the teachers developed their computer skills, whereas $50.4 \%$ of them developed their pedagogical skills. As a result, these acquired computer skills were used in their teaching career.

There is a study by Jahanian and Noroozi (2011) to measure the impact of ICDL training course on enhancing performance of the staff of technical faculties in Tehran University. Data collection done using a questionnaire which reviewed by many university instructors then it was distributed to 120 employees. The results of data analysis showed a valid relation between ICDL training and the skills of new employees such as their accuracy, speed, and amount of achieved work.

Another study conducted by Farid (2015) was mainly focused on outlining the impact of ICT on education in Egypt and the challenges of using ICT in education. The study showed that improved access to ICT in education can aid in helping individuals to compete in a global economy by creating a skilled workforce and facilitating social mobility. The ICT in education has a multiplier effect throughout the education system, by enhancing learning and providing students with new sets of skills. According to Hashemiannejad, Naseri, and Oloumi (2012) who conducted a study comparing the performance rate of Tehran's high school teachers who received training in ICDL courses with the ones who were untrained.

The research, which was done by sampling and collecting data through a questionnaire of 40 questions from 379 teachers, have highlighted the evident impact of ICDL training shown in the significant difference between the ones who received sufficient training and the untrained teachers in terms of using software or hardware educational equipment with a value of $\mathrm{T}=3.08$ and $\mathrm{P}=0.002$. Research made on the ICDL training courses are yet to consider its impact on the youth as an effective entity of the society and the only focus has majorly been directed to teachers and educational institutes and thus, limiting the spectrum of the training.

\section{Methodology}

The conducted study is focused on both qualitative and quantitative research techniques such as questionnaires and interviews. Quantitative techniques such as percentages, tables, and charts were also used to analyze data and were followed by qualitative methods for further data analysis. Survey design has been the basic research method used in this study. The self-administered questionnaire is shown in Fig. 2 below. 


\begin{tabular}{|c|}
\hline Computer Literacy Questionnaire \\
\hline Please answer all questions to help us offer a suitable course based on you \\
\hline 1- Are you? $\quad$ Male $\quad$ Premale \\
\hline 2- Are you? $\bigcirc$ Non-employee $\bigcirc$ Employee $\bigcirc$ Student \\
\hline 3- Your education level $\bigcirc$ None $\bigcirc$ school $\bigcirc$ College $\bigcirc$ University \\
\hline 4- Do you have a pc? $\bigcirc$ Yes \\
\hline 5- Do you enjoy using pc? $\bigcirc$ Yes \\
\hline 6- Do you know using MS Word? \\
\hline 7- Do you know using MS Excel? \\
\hline 8- Do you know using MS PowerPoint? \\
\hline 9- Do you know using MS Access? Ores \\
\hline 10-Do you know using Internet services? \\
\hline 11-Are you using an email service? OYes ONo \\
\hline 12-Do you know English language? $\bigcirc$ Yes $\bigcirc$ No $\bigcirc$ Somehow \\
\hline
\end{tabular}

Figure 2: Self-administered questionnaire of computer literacy

The study went through three consecutive phases: In the first phase, 50 young participants were shortlisted for the ICDL training interview in the city of Mosul during February and April 2019 under an MoU (Memorandum of Understanding) between the International Migration Organization and Tishk International University. This MoU states that Tishk University provides a trainer for the two-month duration while IOM provides trainees and all other requirements necessary for conducting the IT training course.

From the total of 50 candidates from Mosul city, a sample of 27 participants has been selected representing $54 \%$ each for male and female adults. Out of 27 participants, 13 males have been selected, and 14 females have been selected as shown in Figure 3. Later in the second stage of this study, all the 27 participants made a pre-test about ICDL base modules to make sure that they need to take this level. In the second phase of this study, a pre-test was done for all 27 participants to check their IT knowledge based on ICDL basic modules. The pre-test was comprised of 20 different questions which fall into the four parts of ICDL base modules (computer essentials, online essentials, word processing, and spreadsheets), with 5 questions per module. The results of the pre-test proved the need for this training course to the 27 participants.

The total sample has consisted of 27 young participants who completed ICDL training under the MoU initiative, thus, it would be large enough to ensure the stability of results and small enough for the study to be completed within the specified period. The last phase is a post-test which was done on the last day of the training course to measure the amount of learning a participant has acquired within the training period. Post-test was a computer-based test created using iSpring Quiz Maker 7 software which offers more than 10 types of graded and survey questions that can present the questions in compiled HTML file 
format within a specific timing. The iSpring Quiz Maker software can show results to the student at the end of the exam and it can send the results back to the examiner's email if a computer is connected to the internet. This post-test included 20 questions, where 5 questions were asked about each one of the four modules of the ICDL base modules (computer essentials, online essentials, word processing, and spreadsheets). Results of the post-test will be presented and discussed in the next section.

\section{Results}

The results will be presented based on the questionnaire, pre-test, and post-test which were conducted to achieve the goal of this study related to the impact of ICDL in developing IT skills and knowledge. These results are presented according to the four basic modules of the training course.

\subsection{Questionnaire}

The questionnaire which was previously shown in Fig. 2, included 12 questions related to the study objective, in addition to two fields about the name and age of the training candidates. The first field in the questionnaire asked about the age of the participants. A majority of $46 \%$ of participants were between 20 and 30 years old while 19\% were more than 30 years old. The pie chart, shown in Fig. 3 below illustrates the age groups of the course participants.

The first question in the questionnaire asked about the gender type of the participants since gender issue is important in the IT field due to the rapid increase of IT jobs in Iraq, and the pressing need for both male and female representation in the workforce. Fig. 4 below shows the gender types of the 27 participants in the ICDL training course where $52 \%$ of participants are males and $52 \%$ are females. The second question asked about the Personal Computer (PC) equity or availability for the 27 participants. Fig. 5 below shows the PC equity of the participants where the vast majority $74 \%$ have no personal computers and only $26 \%$ stated they have access to personal computers.

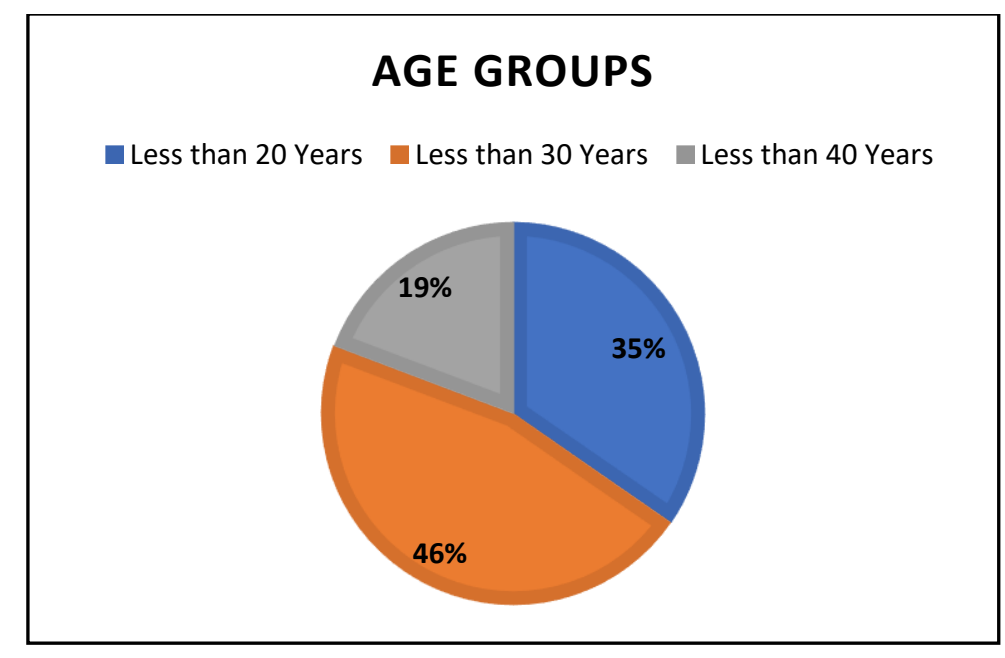

Figure 3: Age groups of participants 


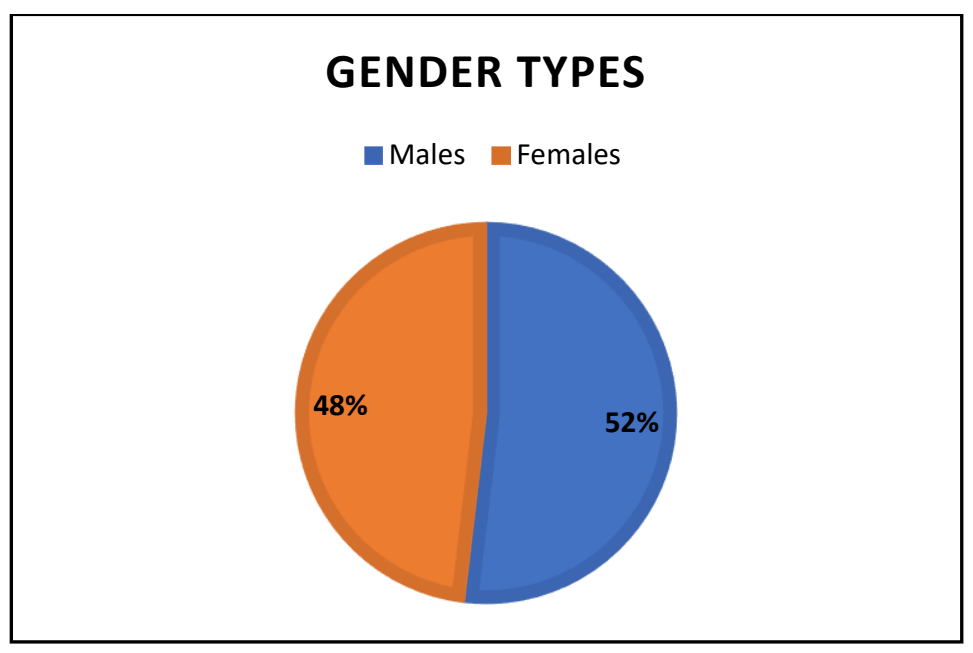

Figure 4: Gender types of the participants

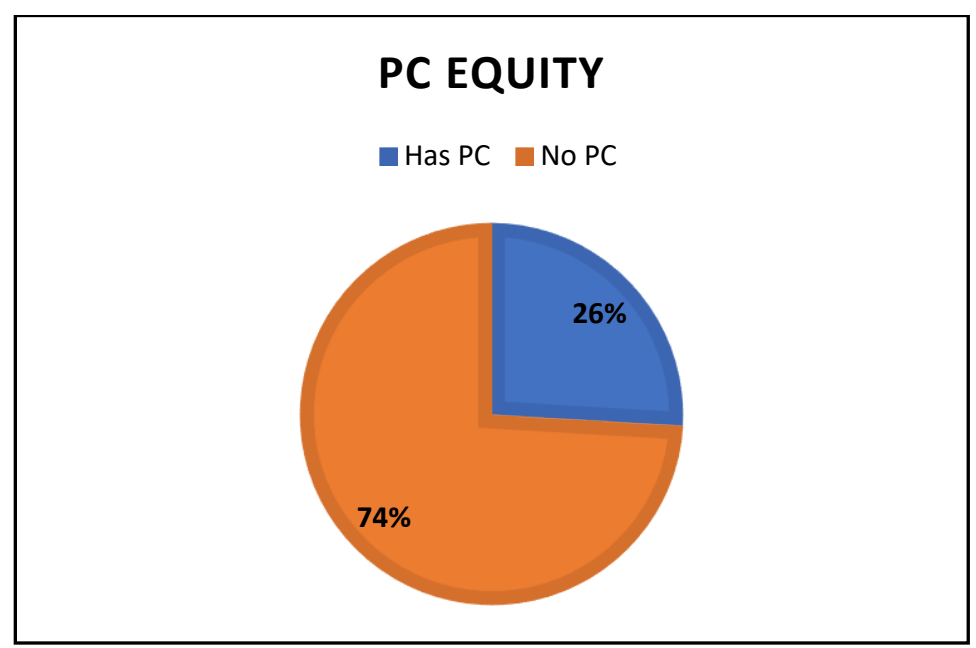

Figure 5: PC equity of participants

When considering the basic skills related to ICDL four modules, the majority of the selected participants, which were approximately $60 \%$, stated that they are familiar with MS Windows. Regarding MS Word, $55 \%$ of the participants stated they are not familiar with MS Word, and 74\% stated their unfamiliarity with MS Excel. For MS PowerPoint, 77\% stated their unfamiliarity, while 96\% stated they are not familiar with using MS Access. Final questions asked about the knowledge of using Internet and email services and results have shown that only a minority of $25 \%$ of the participants stated they don't know how to use basic Internet services, and $37 \%$ stated they are not using email services.

\subsection{Pre-test}

This test was done to evaluate the digital skills of the selected participants related to the ICDL base four modules. However, the test includes 20 questions that were taken from the ICDL Arabia website (https://icdlarabia.org/assessment) which includes many tests including the Basic Skills test that was used 
for this study. The 20 questions were split into 5 questions for each of the 4 ICDL base modules (computer essentials, online essentials, word processing, and spreadsheets). Results of the pre-test will be presented based on the 4 ICDL base modules:

\subsubsection{Computer Essentials}

When considering the basic skills related to the computer, the following five multi-choice questions were asked.

- What is software?

- What is the icon of WIFI networks?

- Which one of these actions could allow malicious programs to access computers?

- Which measure should be taken when dealing with a computer to avoid any health problems?

- Which of the following considerations has the highest storage capacity?

The results of the 5 aforesaid questions have shown that only $41 \%$ of the participants had previous knowledge of what software means ahead of taking the ICDL course modules. However, $56 \%$ of the participants recognized the icon of WIFI networks, which indicates a good student recognition ability. On the other hand, the participants have also shown a prior knowledge of the actions that may cause malicious programs to enter a computer with a $65 \%$. However, the participants demonstrated a lack of knowledge in the results related to the fourth and fifth questions, in which only $44 \%$ of them were familiar with the steps required to deal with the health problem associated with computers, as well as the ability to distinguish between the storage capacity units.

\subsubsection{Online Essentials}

Concerning the skills related to the Internet, four multi-choices questions were asked.

- Which definition is the best for describing pop-ups that appear suddenly while surfing the Internet?

- Which description of phishing is correct?

- What is the name of bookmarks in a browser?

- Which one is the correct definition of the World Wide Web?

The test results for the first question have shown that only $44 \%$ of the participants gave a correct answer which best describes pop-up windows, whereas a percentage as low as $26 \%$ were able to identify the correct description of phishing. The percentage of the correct answers given to the third question was as low as $30 \%$. However, the percentage increased for the fourth and last question in which the test takers managed to identify the correct definition of the World Wide Web with $40 \%$ picking the correct answer.

\subsubsection{Word Processing}

When considering the very basic skills related to Microsoft Word, five multiple choices questions were asked about a keyboard shortcut for pasting, place of showing document name, the icon of changing letters case, the icon of saving a document in another name, and meaning of mail merge feature in MS Word. 
The results have shown that only $33 \%$ of the participants have managed to recognize the keyboard shortcut combination for pasting text. Whereas a better percentage of approximately $59 \%$ of the participants were able to identify the place of showing the document name in MS Word. On the other hand, only $37 \%$ of the participants were able to identify the icon that underlines the text. Besides, the percentage of the correct answers given for the fourth and fifth questions were $48 \%$ and $30 \%$.

\subsubsection{Spreadsheets}

When considering the very basic skills related to Microsoft Excel, five questions were asked. These questions were concerned with the way of hiding headings of cells, the default number of workbooks, changing any cell from general format to date format, place of merged cells, and way of creating an absolute reference for copy/paste in any place within a document. The results indicated a low percentage of true answers for the first question with only $30 \%$. Similarly, the percentage of true answers further declined to $20 \%$ for the second and third questions regarding the default number of worksheets and converting the cell to date format. The percentage of correct answers was additionally low for the given question regarding merging cells with a percentage as low as 33\%. However, the fifth and last question indicated a better understanding of the participants regarding the absolute reference creation with $52 \%$ of correct answers. Fig. 6 below illustrates the pre-test participants' grade evaluation out of 100 in terms of percentages. It was noted that a grade of 5 out of 100 was considered as the least scored grade and 84 as the highest score, the highest percentage shows that $34 \%$ of the participants scored a grade between 21 and 50, whereas only $10 \%$ managed to score a grade above 70 .

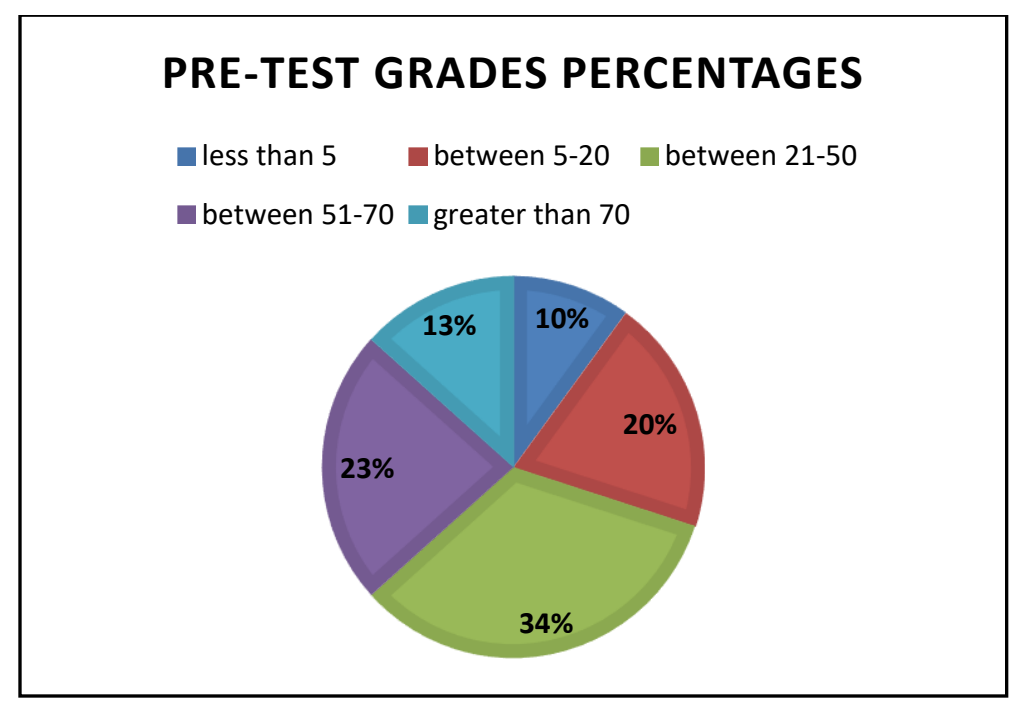

Figure 6: Participants' Pre-Test results (out of 100)

Total grade evaluation for employed participants showed that $17 \%$ of them scored between 5 to 20 grades, whereas $33 \%$ of them received a score between 21 to 50 . However, 50\% of the participants managed to get a score ranged between 51 to 70 . 


\subsection{Post-test}

After a series of weekly training sessions related to the four base modules of ICDL within two months, a computer-based test was conducted to test the participants' level and acquired knowledge during the training course. The test questions and evaluation method which was followed were similar in type to the one conducted in the pre-test phase and the results.

\subsubsection{Computer Essentials}

Five multiple-choice questions related to computer knowledge were asked and the results have revealed that $70 \%$ of the participants enforced their knowledge in the software-related question. It was also evident that the participants were more capable of recognizing desktop icons with a $78 \%$. However, the participants' knowledge of the actions that may result in malicious programs infecting computers has only seen a slight increase, with $63 \%$. On the other hand, $89 \%$ of the participants managed to familiarize themselves with the health problem related to computers, and $78 \%$ of correct answers related to storage capacity unit distinction.

\subsubsection{Online Essentials}

Regarding the online skills related to internet use, the same four pre-test multiple-choice questions were asked. The results have shown that around $89 \%$ of the participants have acquired a better knowledge in terms of recognizing the best description related to pop-up windows. Whereas $67 \%$ of the participants correctly answered the three remaining questions related to phishing, bookmarks, and world wide web definition.

\subsubsection{Word Processing}

The test results of the skills related to Microsoft Word in which the same five multiple-choice questions were asked during the post-test have shown a better understanding and recognition of the keyboard shortcuts, with $70 \%$ of correct answers. However, only $41 \%$ of the participants identified the document name location. On the other hand, $67 \%$ of the correct answers were shared between the underline icon and re-saving the document with another name questions. Besides, $63 \%$ of the participants were able to identify the mail merge feature of words.

\subsubsection{Spreadsheets}

The final section of the post-test with five questions related to spreadsheets indicated that $63 \%$ of the participants managed to know the way of hiding cell headings. The results have also shown that a declined percentage of $48 \%$ of correct answers were given to the question related to the default number of worksheets. However, $67 \%$ of the answers were correct concerning the date format cell conversion. Besides, $59 \%$ of the participants managed to recognize the merged cell icon and $70 \%$ of the answers were correct for absolute reference creation. Illustrated in figure 7 is the post-test participants' grade evaluation out of 100 in terms of percentages.

It was noted that a grade of 37 out of 100 was considered as the least scored grade and 89 as the highest score, the highest percentage shows that $44 \%$ of the participants scored a grade above 70 , whereas only 
$15 \%$ of the recorded scores were between 21 to 50 . When the age and gender criteria were both considered, the below illustrated pre and post-test results in Table 2 and Table 3 are shown in terms of two categories of male and female of the age group from 14 to 29 and ages of 30 and above where the results were recorded in terms of percentages and ranged from the lowest to highest recorded scores.

\section{POST-TEST GRADES PERCENTAGES}

between 21-50 $\quad$ between $51-70 \quad$ greater than 70

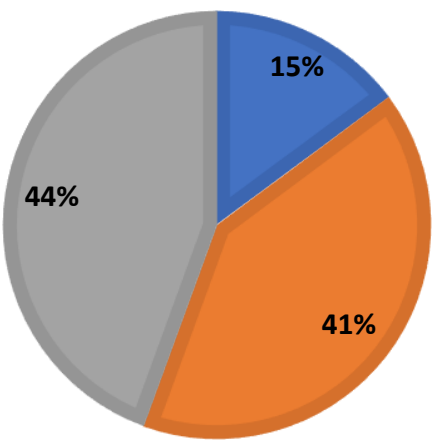

Figure 7: Participants' Pre-Test results (out of 100)

Table 1: Male pre-test and post-test average results

\begin{tabular}{|c|c|c|c|c|}
\hline & \multicolumn{2}{|c|}{ Pre-test Average (\%) } & \multicolumn{2}{c|}{ Post-test average (\%) } \\
\hline Score & $\begin{array}{c}14-29 \text { age } \\
\text { group }\end{array}$ & $\begin{array}{c}30 \text { and above } \\
\text { age group }\end{array}$ & $\begin{array}{c}14-29 \text { age } \\
\text { group }\end{array}$ & $\begin{array}{c}30 \text { and above } \\
\text { age group }\end{array}$ \\
\hline Less than 5 & 20 & 0 & 0 & 0 \\
\hline Between 5-20 & 20 & 0 & 0 & 0 \\
\hline Between 21-50 & 40 & 50 & 25 & 0 \\
\hline Between 51-70 & 7 & 0 & 25 & 0 \\
\hline Greater than 70 & 13 & 50 & 50 & 100 \\
\hline
\end{tabular}

Table 2: Female pre-test and post-test average results

\begin{tabular}{|c|c|c|c|c|}
\hline & \multicolumn{2}{|c|}{ Pre-test Average (\%) } & \multicolumn{2}{c|}{ Post-test average (\%) } \\
\hline Score & $\begin{array}{c}14-29 \text { age } \\
\text { group }\end{array}$ & $\begin{array}{c}30 \text { and above } \\
\text { age group }\end{array}$ & $\begin{array}{c}14-29 \text { age } \\
\text { group }\end{array}$ & $\begin{array}{c}30 \text { and above } \\
\text { age group }\end{array}$ \\
\hline Less than 5 & 0 & 0 & 0 & 0 \\
\hline Between 5-20 & 11 & 50 & 0 & 0 \\
\hline Between 21-50 & 11 & 25 & 11 & 0 \\
\hline Between 51-70 & 56 & 25 & 56 & 75 \\
\hline Greater than 70 & 22 & 0 & 33 & 25 \\
\hline
\end{tabular}




\section{Discussion}

It is evident from the recorded averages for the individual and collective base modules for both the pretest and the post-test that the level of ICDL training takers has notably increased after conducting the training course. Recorded findings have revealed that out of the 27 training participants, a majority of $37 \%$ only managed to score grades between 21-50 during the pre-test. However, the percentage drastically increased in the post-test with $44 \%$ of the participants scoring a grade higher than or equal to 70 . This reveals that regardless of the short length, of course, the overall skills of the participants were adversely improved. The individual skills for each base module have also shown a drastic change in terms of average recorded skill levels. As illustrated in table 3.

Table 3: Pre-test and post-test percentage increase based on the four base modules

\begin{tabular}{|c|c|c|c|c|}
\hline Test section & Module & $\begin{array}{c}\text { Pre-test average } \\
(\%)\end{array}$ & $\begin{array}{c}\text { Post-test average } \\
(\%)\end{array}$ & Percentage increase \\
\hline 1 & Computer Essentials & 50 & 76 & 51.85 \\
\hline 2 & Online Essentials & 37 & 72 & 95.10 \\
\hline 3 & Word Processing & 41 & 61 & 48.78 \\
\hline 4 & Spreadsheets & 32 & 61 & 92.59 \\
\hline
\end{tabular}

It is noted that the recorded average for the Computer Essentials module for post-test was $76 \%$ with a $51.85 \%$ increase evident for the module. A drastic increase was also shown in both the Online Essentials and Spreadsheets modules with a recorded average of $72 \%$ and $61 \%$ compared to the low percentages recorded in the pre-test. The percentage increase for both modules tallied to 95.10 for the Online essentials and 92.59 for the spreadsheet module. The word processing modules illustrated a slight increase going from an average of $32 \%$ to $61 \%$ and with a percentage increase of 48.78 . These findings indicate that the conducted course has aided in increasing the individual skillsets for participants. When the age and gender criteria were put into consideration, the results which were based on the Tables 2 and 3 have shown that both males and females of the two age groups of (14-29 and 30 and above) exhibited a drastic increase in their post-test results when compared to their previous recorded scores in the pre-test. Males of the age group of 14-29 years old have shown an increase in the range of results scored in the post-test where 25 percent of them managed to score between 21-50 and 51-70 marks, with 50 percent of them scoring more than 70. On the other hand, those of age group of 30 and above all managed to score above 70 . Females of age 14-29 improved their results in the post-test with 33 percent of them scoring results of 70 and above with 56 percent of them also managing to score between 51-70 whilst all the low results between 0-20 were eliminated. The age group of 30 and above exhibited a major change in their recorded scores with 75 percent of them scoring between 51 to 70 , while the rest of the 25 percent managed to score 70 and above.

\section{Conclusion}

In conclusion, the positive impact of the ICDL skills training that targets the young generation is highly prominent. The crucial role played by the ICT skills in the advancement of youth will lead to enhanced progress of the students' academic journey and in turn, provide competent workforce represents. 
Generally, the results of the ICDL trainees pre and post-tests in which the study was carried out have shown that regardless of the minimum exposure or access to computers of those trainees, the integration of this training to their daily activities enhanced their skills in a drastic measure. The attitude and response of those participants gradually improved with each training session and as a result, their final test showed a peak in their scores within each section of the base module. According to the study findings, most of the participants improved their online and spreadsheets skills by an increase of 90 percent from their previously recorded results and around 50 percent increase for the computer and word processing essentials. The gender gap was not entirely evident in the conducted test as the participation rate of females was high and reached an approximation of 50\% in total, however, female, and male counterparts of both age groups, proved competent during the tests, with males proving to be more successful in both age groups. This leads to the conclusion that more efforts are needed to rally females into being involved in the computer world and to challenge their male counterparts in computer literacy and in taking their future path in computer science majors. Additional IT skills training such as ICDL courses are also recommended to be given to IDPs and war-torn areas where a large percentage of youth lack the basic IT skills, as it is deemed useful to the recovery of their community and in turn, provide an adequate future to shape the framework of their returns.

\section{References}

Abuhmaid, A. (2011). ICT training courses for teacher professional development in Jordan. Turkish Online Journal of Educational Technology, 10. 195-210.

Al-Hakeem, S., M., \& Abdulrahman, M. (2017). Developing a new e-exam platform to enhance the university academic examinations: The case of Lebanese French University. International Journal of Modern Education and Computer Science, 9(5), 9-16. doi:10.5815/ijmecs.2017.05.02

Csapo, N. (2002). Certification of computer literacy. T.H.E. Journal, 30(1), 46,48,50-51.

Farid, D. S. (2016). The impact of information and communication technology (ICT) on education in Egypt. International Journal for Research in Business, Management and Accounting, 2(3), 171-191. Retrieved from https://www.gnpublication.org/index.php/bma/article/view/592

Hashemiannejad, F., Naseri, N., Naseri, M., \& Oloumi, S. (2012). Comparison of the performance trained teachers in ICDL training courses with untrained teachers in high schools of Tehran. International Conference on Education Technology and Computer (ICETC2012) IPCSIT vol.43. Singapore.

Jahanian, R., \& Noroozi, Z. (2011). The effect of ICDL training courses to improve the performance of the staffs of technical faculties campus in the university of Tehran. Innovation in management education. Journal of Modern Thoughts in Education, 6(2 (22)), 29-45. https://www.sid.ir/en/journal/viewpaper.aspx?id=214284

Leahy D., \& Dolan D. (2010). Digital literacy: A vital competence for 2010. In: Reynolds N., TurcsányiSzabó M. (eds) Key competencies in the knowledge society. KCKS 2010. IFIP advances in information and communication technology, Vol. 324. Springer, Berlin, Heidelberg. 